\title{
Campos Autônomos
}

Floriano Romano*

RESUMO: O texto trata do ato falante e da experiência do corpo como alternativas às formas de poder estabelecidas na sociedade contemporânea e da construção de outro lugar sonoro a partir da multidão, onde o ruído dos corpos no espaço público é o elemento dissonante do discurso globalizado representado pela sonoridade urbana e sua rotina.

Palavras-chave: multidão, território, corpo sonoro

ABSTRACT: The text deals with the speaker act and the experience of the body as alternative to of established forms power in contemporary society and with the construction of another place sound from the multitude, where the noise of the bodies in the public arena is the dissonant element to the globalized discourse represented by urban sonority and its routine.

Keywords: multitude, territory, sounding body

\footnotetext{
* Floriano Romano é artista visual e sonoro. Criou o programa de rádio Oinusitado que foi um ponto de encontro da cena de arte sonora carioca de 2002 a 2004. Trabalha com intervenções urbanas e sonoras, abertas à participação do público. Recebeu vários prêmios, entre eles, o Prêmio MARCANTONIO VILAÇA 2012 da Funarte e a Bolsa de Apoio à Pesquisa Artística 2008 da Funarte. Participou da

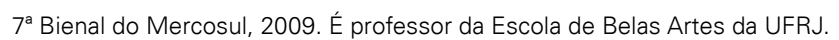


A sociedade contemporânea constitui-se metaforicamente de redes. Redes que se misturam graças às novas possibilidades de acesso generalizado ao conhecimento. Redes de experiências e de processos que se misturam graças às distâncias relativas do mundo digital. Redes de poderes de quem retêm esse conhecimento e que se aplicam no cotidiano da sociedade contemporânea, em seus aspectos macro e micropolíticos. Seu ethos está intimamente ligado à tecnologia. Ela é a condutora de um discurso que se impõe como único, (quase) autêntico. Discurso esse que é pura repetição, a fala da concretude. Um lógos oco e sem reflexão. A tecnologia representa o poder constituído.

Ao ouvi-lo, percebê-lo, acessá-lo estamos como os discípulos de Pitágoras, ouvindo vozes. Acusmatas, aqueles que não vêem a origem da fonte sonora. O filósofo, ao falar por trás da cortina, em sua invisibilidade, tornou o lógos espacial, som em toda parte. A presença do discurso.

O capitalismo contemporâneo busca essa ubiquidade, essa presença, através do uso da tecnologia para a repetição e não para a vivência criativa. Busca preencher nossa experiência com fragmentos disponíveis de outras experiências, que não se completam em um todo. Só sabemos a parte do processo que nos é destinada e que nos toma o tempo de uma vida para seu consumo. Apreendemos um discurso que imita secretamente as vozes que nos acostumamos a ouvir desde a infância. Esse discurso que reconhecemos e percebemos como uma presença ubíqua e controladora. Que está sempre à escuta para ouvir o que possa divergir de sua hegemonia. Que absorve os discursos ressonantes e dissonantes.

Essa fala ubíqua, hegemônica, organiza o dissenso, orienta o corpo passivo, arbitra e pune o desvio. Elucida parcialmente as coisas do mundo e dá a elas significado apenas segundo sua ordem. Contra ela se coloca a fala dissonante, a criação de palavras, a nomeação do mundo, a experiência do corpo, os atos em que o corpo se entrega à transformação. Em um mundo sem deuses ou em que deus se tornou a tecnologia, esse é o nosso desafio: refutar a passividade e reinventar os significados da vida comum. Ser falante. 
Nas florestas às vezes ouve-se uma voz, o vento entre as árvores. Nas barrigas as crianças ouvem o canto de suas mães. Na mitologia os deuses aparecem e nos ensinam falando conosco. Por "voz", "fala”, ora podemos entender o som humano propriamente dito, o ruído do mundo metaforizado, os ruídos industriais da cidade. Mas sua maior expressão contemporânea é a fala política das multidões que tomam as ruas. Porque é além do discurso, a presença física no espaço que se opõe à ilusão acusmática. Contrária à ubiquidade do poder invisível. Sobrepondo-se ao excesso de informação e ao otimismo que tudo aceita com docilidade. Unidos criam um lugar através de seus cantos, desinteressados de seus significados, mas interessados em quão ruidosos podem ser. Produtoras de ruído, interferentes, as multidões tomam as ruas, o espaço destinado à discussão política retomado do poder invisível.

O espaço da fala. A fala como ressonância."Falar" aqui é reagir à repetição, uma outra forma de interpretar a experiência da vida, ter seu próprio som, rugir para o mundo com sua própria voz. A Voz é uma ampliação do alcance do corpo humano para dentro e para fora. Para fora, seu alcance físico, onde o som pode chegar com o deslocamento das partículas do ar. Por dentro, na interioridade, na abstração da linguagem que ela carrega.

A cidade, desde seu surgimento, mudou radicalmente a vida humana; os discursos, as vozes não são apenas dos indivíduos, mas das máquinas e dos sons industriais. A cidade sonora.

Se o homem cria a música para subjugar o caos ruidoso do mundo, como procede ele frente à nova paisagem sonora que nos envolve ritmicamente? Como dominar e transformar em música ruídos sem expressão e criados por sistemas que mantém o poder e o status quo do poder hegemônico? A rede ruidosa da cidade maquínica informa sobre suas prioridades e poderes.

Não iria nossa mudez contra o empoderamento do humano pela tecnologia? Não estamos mais do que nunca preparados para falar por nós mesmos, instrumentalizados pela tecnologia e pelo conhecimento acumulado por séculos? Desvios devem surgir para rivalizar com essa hegemonia e falas autorais devem criar pontos de fuga para equilibrar a percepção do mundo. A experiência não pode ser percebida por um filtro, uma fala única, um só ponto de vista, onde existem milhares deles, nossas interpretações, nossas divergências, nossos gritos que o otimismo tecnológico parece desprezar. 
O poder e o conhecimento gerados pela tecnologia não podem se concentrar para sempre em mapas, guerras e sistemas de controle. Deve haver um impulso contínuo em direção à liberdade e esse impulso se dá com nossos corpos. É e sempre será a hora de produzir micropolíticas que se insiram nesse discurso como o som se infiltra por nossos ouvidos, atravessa a fresta dos dedos, utiliza a carne dos dedos para transmitir suas vibrações.

Uma vez poderosos, não podemos aceitar formas de controle que venham de fora para dentro, nem pagarmos o usufruto tecnológico com docilidade. Ao invés disso, devemos transformar a tecnologia com a mesma sagacidade da multidão, reorganizar sua semântica funcional. O corpo não pode se limitar ao seu uso como ferramenta, da mesma forma que o conhecimento não pode se aplicar eternamente na amarga repetição da rotina. Os desvios falantes surgem para compensar essa disputa pelo imaginário do mundo.

III

A medição e a pesquisa buscam esmiuçar esse mundo ruidoso da cidade em seus decibéis. Mas as paisagens sonoras não contêm os elementos da transformação social. A transformação é cultural e a natureza autêntica. O caos é sua potência e de onde provém seu equilíbrio. Para nós, ela é um estático conjunto de fenômenos que podem ser medidos e conhecidos (e agora, salvos da destruição). Apenas conhecendo os dados de seus fenômenos não superamos seus limites, não alcançamos todos os seus significados e não nos autorizamos a penetrá-la.

Terminamos por viver o mundo urbano como nossa natureza, algo que criamos e sustentamos, inclusive sua paisagem sonora, com seu descontrole, seus ruídos, sua singularidade, menosprezada em seu potencial, por nossa falta de tempo, nossa dedicação religiosa ao trabalho. Essa temporalidade urbana tem um ritmo, um ritmo que nos faz dançar. Um ritmo ilusório, delirante, sem relação com nada, pura repetição.

Por isso o corpo sonoro, falante, é de extrema importância para a arte e para a política. O envolvimento físico como prolongamento do pensamento, uma vez separados do plasma ruidoso, tendemos a vê-lo como inconveniente, assustador, caótico. Da manipulação da natureza geramos novas naturezas, que ocupamos e vivenciamos como autênticas. Projetamos sociedades futuras, esquecendo-nos de projetar homens futuros, crentes na ciência e na tecnologia como formadoras do cidadão tecnológico. Esquecemos da criação como algo capaz de ampliar nossa interpretação do mundo e que permite que nos expressemos sobre as transformações que vivemos. 
Quando falamos, empurramos moléculas de ar à frente. Ocupamos o ar. A potência do som que emitimos gera um campo sonoro em torno de nós na mesma proporção da amplitude de nossa voz. Toda fala, toda emissão de som que produzimos com nosso corpo, gera um campo sonoro autônomo e ativo dentro da paisagem sonora do mundo com seu deslocamento mecânico e o alcance íntimo de seu significado.

Quando falamos, nos dirigimos a alguém ou a algo. É uma projeção sonora externa e interna. Ocupação de um território, de um espaço físico, em torno e dentro de nós. Fala que nos diferencia como habilidade, a capacidade de descrever o mundo e fazê-lo com clareza. Fisicamente o som de nossa voz atua ao mesmo tempo em que nossa audição se empenha em interpretar o que ouvimos.

O som ocupa o espaço físico do mundo ao redor de sua fonte e, com sua invisibilidade, estimula o potencial imaginário dos ouvintes, impulsionando-os em suas memórias. Ouvindo, recorremos sempre ao nosso repertório e encaixamos continuamente os fragmentos em nossas experiências vividas. O início da criação é a fala. Fluindo de voz em voz, a fala produz ressonâncias. Para além de nosso território se propaga nosso discurso.

O encontro dessa fala com a vivência do corpo é a poesia sonora. Produzir essa fala é criar um campo autônomo, pensar a arte e a ocupação política das ruas ao mesmo tempo, porque o som produz territórios desde o indivíduo até a multidão, campos de autonomia que se dão na esfera pública. É a escuta de tal forma sensível que nos demanda repensar o nosso senso de percepção.

\section{Referências}

LABELLE, Brandon. Acoustic Territories: Sound Culture and Everyday Life. Londres: Continuum, 2010.

ALŸS, Francis. A Story of Deception: Patagonia, 2003-2006. Buenos Aires: Fundacíon Eduardo F. Constantini, 2006.

NANCY, Jean-Luc. Listening. Bronx, Nova York: Fordhan University Press, 2007.

POE, Edgar Allan. O homem da multidão. In: Obras Completas. Rio de Janeiro: Nova Aguilar, 2001.

TOMÁS, Lia. Ouvir o lógos: música e filosofia. São Paulo: Ed. UNESP, 2002.

ULPIANO, Claudio. Gilles Deleuze: a grande aventura do pensamento. Rio de Janeiro: Funemac Livros, 2013.

ZIZEK, Slavoj. O violento silêncio de um novo começo. In: HARVEY, David; ŽIŽEK, Slavoj; ALI, Tariq et al. Occupy: movimentos de protesto que tomaram as ruas. São Paulo: Boitempo Editorial, 2012. 